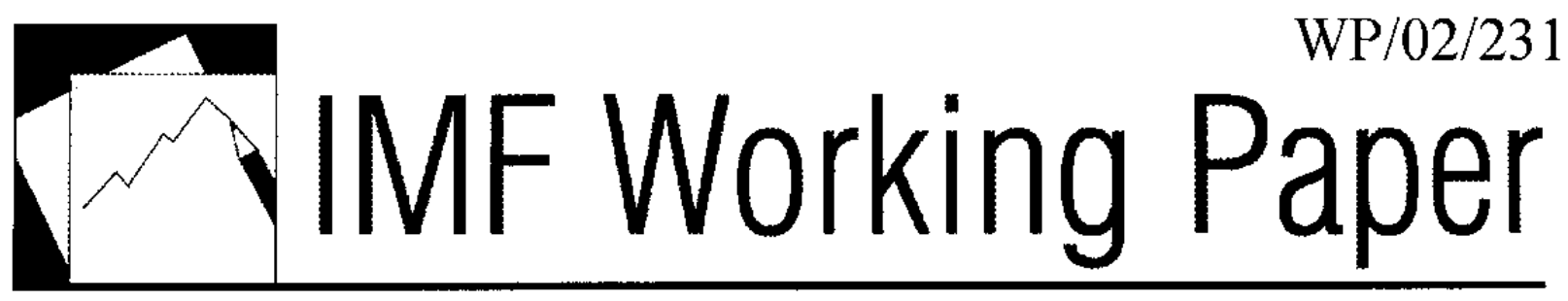

\title{
Leading Indicators of Growth and Inflation in Turkey
}

Daniel Leigh and Marco Rossi 



\title{
IMF Working Paper
}

European I Department

\section{Leading Indicators of Growth and Inflation in Turkey}

\author{
Prepared by Daniel Leigh and Marco Rossi ${ }^{1}$ \\ Authorized for distribution by Juha Kähkönen
}

December 2002

\begin{abstract}
The views expressed in this are those of the author(s) and do not necessarily represent those of the IMF or IMF policy. Working Papers describe research in progress by the author(s) and are published to elicit comments and to further debate.
\end{abstract}

Growth and inflation in Turkey have been volatile over the last two decades. It would, therefore, be useful to identify indicators that anticipate economic conditions and inflation. This paper investigates the predictive performance of economic indicators for inflation and real output growth in Turkey. We find that (i) the forecasting ability of individual indicators is unstable; but that (ii) a suitable combination of these unstable forecasts yields a forecast that reliably outperforms that generated by an autoregressive model. We then propose a twostage combination forecast obtained by taking the median of the top five performing individual forecasts. This two-stage forecast reliably improves on autoregressive benchmarks and outperforms the combination forecast based on all the individual forecasts.

JEL Classification Numbers:E31, E32, E37, E58, F43, O52

Keywords: Growth, inflation, combination forecasts, leading indicators, inflation targeting, Turkey

Authors' E-Mail Addresses: Danielleigh76@yahoo.com, mrossi@imforg

\footnotetext{
${ }^{1}$ The authors would like to thank Alex Hoffmaister, Juha Kähkönen, and participants in the European I Department internal seminar for helpful comments and suggestions. The usual disclaimer applies. Daniel Leigh, Johns Hopkins University, was Summer Intern at the IMF when the paper was prepared.
} 


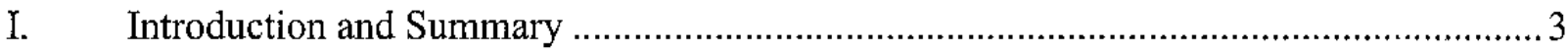

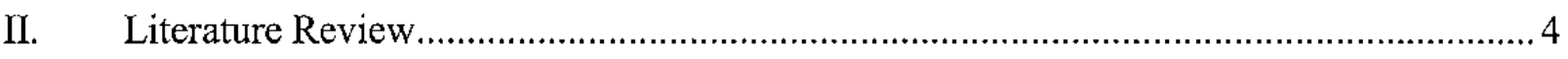

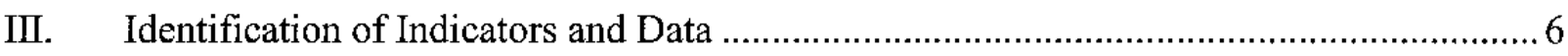

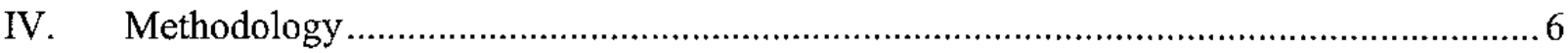

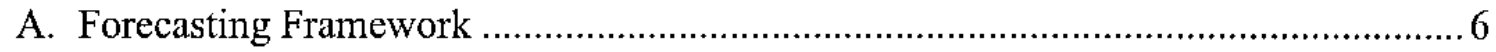

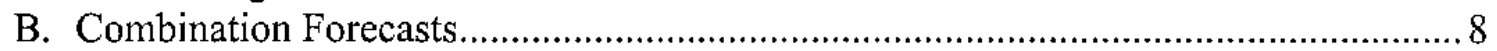

C. Concurrent Forecasts ...................................................................................

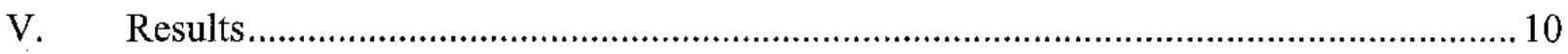

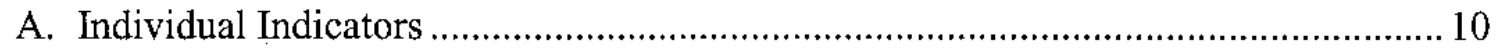

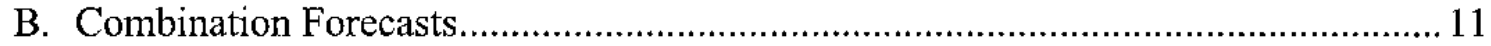

C. Concurrent Predictions of GDP ................................................................. 12

D. Performance of Two-Stage Combination Forecasts Over the 2000-02 Period........ 12

Figures

1. Real GDP Growth and Growth Uncertainty, 1964-2001 ..................................... 13

2. Inflation and Inflation Uncertainty, 1964-2001 ............................................ 14

3. Growth over the Current Quarter...............................................................22

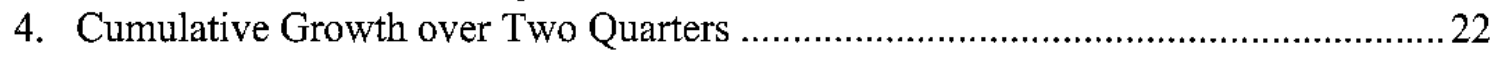

5. Cumulative Growth over Three Quarters ............................................................ 23

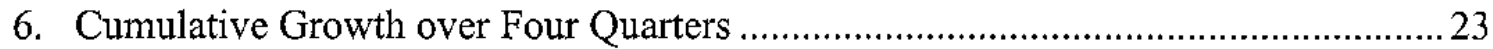

7. Cumulative Growth over Three Months ............................................................ 24

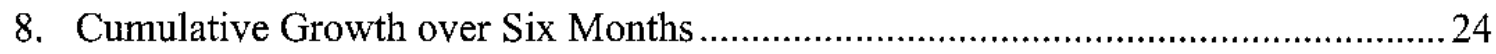

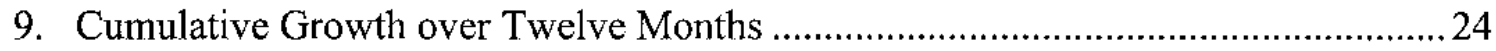

Tables

1. Series Descriptions and Data Sample Periods, 2001-02 …................................. 15

2. Real GDP Growth Out-of-Sample Forecasting Results, 1992-2002 ....................... 16

3. Industrial Production and CPI Inflation Out-of-Sample Forecasting Results, 1992-2002 ............................................................................... 18

4.1 Combination Forecasts Out-of-Sample Forecast Accuracy over

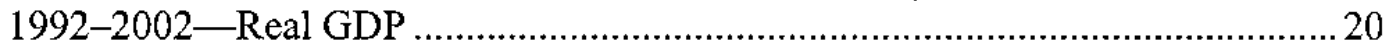

4.2 Combination Forecasts Out-of-Sample Forecast Accuracy over 1992-2002 —-Industrial Production............................................................. 20

4.3 Combination Forecasts Out-of-Sample Forecast Accuracy over

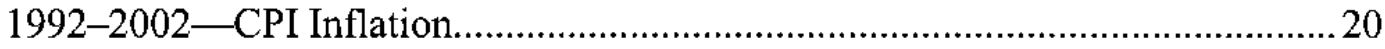

4.4 Combination Forecasts Out-of-Sample Forecast Accuracy over 1992-2002-Current Quarter Real GDP.....................................................20

5. Current Quarter Real GDP Growth....................................................... 21

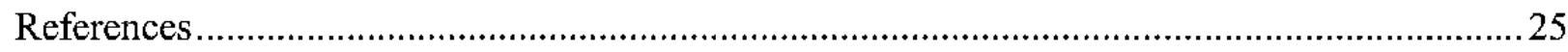




\section{INTRODUCTION AND SUMMARY}

Turkey's growth and inflation have been highly volatile over the last two decades (Figures 1 and 2). Since the late 1980s, booms and busts have characterized the business cycle in Turkey. Since 1994 alone, Turkey has experienced three severe recessions, two of them triggered by financial crises. The lack of macroeconomic stability has not only negatively affected economic growth and inflation, but has also increased their volatility. Inflation has increased dramatically - making Turkey in recent years the country with the highest inflation among emerging and EU accession economies-while real GNP growth has decreased on average. At the same time, inflation and growth uncertainty - as measured by the conditional variance-has increased, making forecasting growth and inflation even harder.

Identifying indicators that could help anticipate economic conditions and inflation is therefore topical, in particular as Turkey moves to an inflation targeting regime. ${ }^{2}$ Inflation targeting requires central banks to react promptly when the inflation forecast deviates from target. Given that the impact of monetary policy on inflation occurs with a lag, central banks usually rely on a series of tools to anticipate future price pressures and changes in economic activity. In addition to structural macroeconomic and short-term models, a battery of leading indicators of growth and inflation are used to forecast, at any given point in time, growth and inflation prospects over the following 3 to 12 months. These forecasts could then inform the internal policy debate.

This paper investigates the predictive performance of economic indicators for inflation and real output growth in Turkey. The aim is to test the information content of several indicators in the context of high and volatile growth and inflation. Such information would complement that obtained from structural and short-term models. ${ }^{3}$ The analysis focuses on monthly data on 42 candidate indicators over a span of up to 16 years (1986-2002). These indicators include measures of real activity, monetary aggregates, and asset prices.

\footnotetext{
${ }^{2}$ Under the 1999 IMF-supported program, the Central Bank of Turkey (CBT) intended to introduce inflation targeting (IT) in 2002 as the exchange rate band widened and control of domestic monetary conditions improved. The crisis in February 2001 and the introduction of the float left the economy without a nominal anchor, underscoring the importance of moving toward IT promptly. Preparatory work was speeded up with a view to introducing IT by end2001. Amid financial turbulence in the aftermath of September 11, the CBT felt, however, that additional time was needed to prepare for IT. The CBT has recently announced that the adoption of IT is likely to be delayed until 2003.

${ }^{3}$ In a companion paper, Leigh and Rossi (2002) look at the exchange rate pass-through as an additional source of information to assess underlying inflationary pressures.
} 
In light of the high volatility of growth and inflation in Turkey, the findings are not surprising, yet informative and in line with the literature:

- Few leading indicators on their own improve on the autoregressive benchmark in out-of-sample forecasts. Moreover, the forecasting ability of individual indicators is unstable; that is, finding a predictor that predicts well for one forecasting horizon does not guarantee that it will predict well for a different horizon. For example, simulated out-of-sample forecasts of the growth rate of industrial production using the nominal exchange rate are more accurate than a simple autoregressive (AR) benchmark for the 18-month forecasting horizon, but less accurate than the AR benchmark for 6- and 12month horizons.

- Suitable combinations of the various unstable forecasts yields a forecast that reliably outperforms the AR. The median of all the individual forecasts consistently performs better than the AR benchmark for both inflation and for output growth for all the forecasting horizons considered. The implication for economic forecasting is that one should prefer the combination forecast to any individual forecast, or indeed to a forecast with estimated weights, given the problems of accurately estimating them.

- The two-stage combination forecast proposed in this paper outperforms both the AR and the combination forecast based on the full set of indicators. We propose a two-stage combination forecast obtained by taking the median of only the top five performing individual forecasts. This two-stage forecast consistently and reliably improves on AR benchmarks and outperforms the combination forecast based on the full set of individual forecasts. Despite the improvement over the AR benchmark, inflation and output growth forecasts based on a combination of indicators remain tentative, however, because of the large standard errors of the estimates. This is a rather common result in the literature, as discussed in the next section.

- The performance of these two-stage forecasts over the period 2000-02 is, however, mixed. The two-stage combination forecasts, proposed in this paper, are used to predict real GDP growth and CPI inflation for the period 2000-2002. The forecast for GDP growth tracks the actual growth rate closely and correctly anticipates the main contraction associated with the 2001 crisis and the subsequent recovery. By contrast, the forecast of inflation is less accurate.

\section{LITERATURE REVIEW}

Nonfinancial variables have been extensively used to forecast growth and inflation, but with limited success. The literature on forecasting inflation and output growth using economic indicators is massive. One strand of the literature focuses on forecasting using nonfinancial variables such as the output gap and unemployment. Many nonfinancial variables have some predictive content for output growth, based on in-sample statistics, as documented by Stock and Watson (1999a). However, the individual indicators are apparently unreliable in their ability to 
forecast well out of sample. Using data from seven industrialized countries over a 41-year period, Stock and Watson (2001) show that good predictive performance by a nonfinancial indicator in one period seems unrelated to its performance in a later period. Similarly, forecasts of inflation using nonfinancial indicators have been found to be unable to improve reliably upon univariate benchmarks. In the Unitcd States, the unemployment-based Phillips curve with a constant NAIRU has recently been unstable, incorrectly predicting accelerating inflation during the 1995-2000 period, as documented by Gordon (1997 and 1998). The ability of output gap and unemployment models to forecast inflation in Europe appears to be even more limited than in the United States, as found by Marcellino, Stock, and Watson (2000).

A growing literature has focused on asset prices to forecast inflation and growth, but again with mixed results. Movements in exchange rates, equity values and prices for real assets, such as housing and real estate, are playing an increasingly important role in many economies and are increasingly important for policymakers. Stock and Watson (2001) and Goodhart and Hofmann (1999 and 2000) examine the predictive power of asset prices for inflation and output growth across different countries. Overall, they find that individual asset prices are not consistent in their forecasting ability. Variables with good in-sample explanatory power often perform badly in out-of-sample forecasts.

More recently, the attention has shifted toward testing the predictive power of combined leading indicators. Some authors favor forecasts made up of combinations of leading indicators, such as weighted averages or financial conditions indices. For example, Stock and Watson (2001) find that "the median of the forecasts of output growth based on individual asset prices produces a forecast that is reliably more accurate than the AR benchmark, even though the individual forecasts used to compute the median are not." Similarly, Okina and Shiratsuka (2001) compare the predictive ability of individual leading indicators and of combination forecasts for Japanese data for two periods, 1987-90 and 199194. They find that combined forecasts based on the median and trimmed means of all the individual forecasts benchmarks perform better than AR benchmarks in both sample periods.

Additional research has tested the predictive power of leading indicators in the context of emerging markets. The literature on the forecasting ability of individual indicators and of combination forecasts focuses on industrialized economies with low and stable inflation. ${ }^{4}$ Whether the results hold in economies with high and volatile inflation is the subject of current research. Chauvet (2000) investigates the ability of asset prices and other economic indicators to forecast inflation turning points in Brazil. She finds that although the leading indicators perform well for the 1994 to 1999 period, they have weak ability over the longer 1980 to 1999 period that includes the hyperinflationary episodes of the $1980 \mathrm{~s}$ and several stabilization plans.

\footnotetext{
${ }^{4}$ For instance, Stock and Watson (2001) examine evidence from Canada, France, Germany, Italy, Japan, the United Kingdom, and the United States.
} 


\section{IDENTIFICATION OF INDICATORS AND DATA}

In-sample tests are not the sole approach to select candidate indicators. A common method for identifying potential predictors is to use in-sample tests such as Granger causality tests. However, the literature on forecasting suggests that models with very good in-sample fits do not necessarily perform well out of sample. For instance, Stock and Watson find that "a significant Granger causality statistic contains little or no information about whether the indicator has been a reliable predictor" (Stock and Watson, 2001, p. 2). ${ }^{5}$

A wide range of indicators is considered. The candidate indicators are chosen according to (i) whether there are empirical and/or theoretical reasons to believe that they have predictive power; (ii) their availability with monthly-for the consumer price index (CPI) and industrial production (IP) — and quarterly — for GDP — frequency; and (iii) their sample length. The indicators include measures of economic activity (index of industrial production, the output gap as measured by the one-sided Hodrick-Prescott filter, capacity utilization), price indices (wholesale and consumer), commodity prices, monetary aggregates (M1 to M3), international reserves, asset prices (interest rates, foreign exchange rates, stock prices, price-earnings ratios, dividend yields, land prices, the spread between U.S. and Turkish short-term interest rates). We use both nominal and real variables since either can affect real output and inflation, if there are nominal rigidities in the economy.

The data come from the IMF's International Financial Statistics database, the Central Bank of Turkey, and the Ministry of Finance of Turkey. Table 1 summarizes the data series. Over the entire 1986-2002 period, we chose 41 indicators that are available with a monthly frequency, and 42 indicators that are released quarterly.

Three transformations are applied to the data. We take the logarithm of the data series and the first and second differences. We seasonally adjust the series that display significant seasonal variation. Seasonal adjustment is made using the $\mathrm{X}-11$ additive method used by the U.S. Bureau of the Census. The seasonally adjusted series are indicated by "SA" in Table 1 . Real variables were computed by deflating the nominal variables with the CPI. After the various transformations, the total numbers of variables used for forecasting are 67 for IP and CPI, and 71 for real GDP.

\section{Methodology}

\section{A. Forecasting Framework}

The methodology draws on Stock and Watson (2001), but is adapted for forecasting at monthly and quarterly frequencies. We consider models for forecasting real output growth

${ }^{5}$ Stock and Watson (2001) avoid the problem of fitting too complicated a model by calculating simple linear bivariate forecasts and taking their median. 
and price inflation using a sample of monthly and quarterly observations. Real activity is measured by (i) the index of quarterly real GDP (GDP) and (ii) the index of industrial production (IP), while the price level is measured by the consumer price index (CPI). The forecasting models use a candidate predictor, $X_{t}$, to predict the value of the variable of interest $h$ months ahead, $y_{t+h}^{h}$. For real GDP, we consider horizons of 1, 2, 3, and 4 quarters. For IP and the CPI, horizons of 3,6 , and 12 months are considered. The model can be written as:

$$
y_{t+h}^{h}=\mu+\alpha(L) y_{t}+\beta(L) X_{t}+\varepsilon_{t+h}^{h}
$$

where $\alpha(L)$ and $\beta(L)$ are lag polynomials. All the forecasting models include lags of the dependent variable, $y_{t}$. The models differ with respect to which candidate predictor is included. This $h$-step ahead approach contrasts with the common method of estimating one-step ahead projections and then iterating the model forward to get $h$-step ahead projections. Since the same horizon is used for estimation as for forecasting, the approach reduces the possible impact of specification error in the one-step ahead model.

The dependent variables were transformed to be stationary. We run Augmented Dickey-Fuller (ADF) tests for the entire sample period 1986-2002. These tests suggest that the $\log$ of IP and GDP are best modeled as I(1). There is some ambiguity, however, regarding the order of integration of the log of CPI. The test just fails to reject the null hypothesis of a unit root in the first difference of the log of CPI at the 5 percent level. However, the null hypothesis of nonstationarity in the second difference of the log of the CPI (i.e., the first difference of inflation) is rejected at the 1 percent level. The out-of-sample forecasting exercises are conducted for both transformations. The forecasts proved to be more accurate using the I(2) transformation and only the results obtained using this transformation are reported in the paper. Thus for the CPI, $y_{\mathrm{t}}$ is the first difference of inflation, $\Delta \log \left(C P I_{t} / C P I_{t-l}\right)$, while for IP or GDP, $y_{t}$ is their growth rate, $\Delta \log \left(I P_{t}\right)$ or $\left.\Delta \log \left(G D P_{t}\right)\right)$. The multistep forecasts investigate the predictability of the log of the level of the variable, after imposing the I(1) or I(2) transformation. For real GDP, $y_{t+h}^{h}=\log \left(G D P_{t+h} / G D P_{t}\right)$ and for IP, $y_{t+h}^{h}=\log \left(I P_{t: h} / I P_{t}\right)$, and for prices, $y_{t+h}^{h}=\log \left(C P I_{t+h} / C P I_{t}\right)-h \log \left(C P I_{t} / C P I_{t-1}\right)$. The $y_{t+h}^{h}$ series can be shown to be stationary.

At each stage of the forecasting process, lag lengths to estimate the models are chosen to minimize the Akaike Information Criterion (AIC) and used to forecast out of sample. The benchmark autoregressive forecasts omit the $X_{t}$ terms in [1]. For the autoregressive forecasts, the lag lengths for $\alpha(L)$ were between zero and twelve. The bivariate forecasts for the individual leading indicators include both the autoregressive and the $X_{i}$ terms. For the bivariate forecasts, the lag lengths for $\alpha(L)$ were between zero and twelve and between one and twelve for $\beta(L)$. 


\section{B. Combination Forecasts}

Combination forecasts are constructed from individual forecasts, each based on a candidate leading indicator. The theory of optimal linear forecast combination-Bates and Granger (1969) and Granger and Ramanathan (1984)-suggests combining forecasts by regressing actual realizations on the individual forecasts. The weight on each predictor in the combination forecast would thus be the estimated regression coefficient from a regression of the true future value of the series being forecasted onto the various forecasts, subject to two constraints: no constant term in the regression, and the weights sum to one. ${ }^{6}$ In practice, the estimates of those weights over short sample periods are imprecise due to colinearity among the large number of forecasts to be combined. To overcome this problem, Stock and Watson (2001) suggest either weighting the forecasts inversely in proportion to their historical mean squared forecast error (MSFE), using equal weights (simple average), or using the median or trimmed mean forecasts. The median and trimmed mean methods are robust to outliers while the simple and weighted averages are not. Below, we report results for the median combination forecasts.

Each forecast is computed out of sample. All estimations, lag length selection, regression, and forecasting is based solely on data available through date $t$. Thus we do not allow the forecasts to use information that would have been unavailable at the time that the predictions were made. In this sense, the forecasting exercises simulate real-time actual forecasting. This procedure generates a series of forecast errors $\left(y_{t+h}^{h}-\hat{y}_{t+h}\right)$. The out-of-sample forecasting exercises start in 1992, after six years of in-sample data have accumulated, and end in early 2002.

We compare the performance of the various forecasts relative to the autoregressive benchmark forecast. To measure the forecasting performance, we use the mean squared forecast error (MSFE) of the candidate forecasting model relative to the MSFE of the AR benchmark over the same sample period. When the ratio is less than one, it indicates that the forecasting model is more accurate than the AR benchmark. Using the MSFE to evaluate forecasting performance is standard practice in the literature. However, we also evaluate the performance using an alternative loss function, the mean absolute error, but the results are qualitatively the same. ${ }^{7}$

\footnotetext{
${ }^{6}$ See Diebold and Lopez (1995) for an extensive review of forecast evaluation and combination.

${ }^{7}$ Standard errors for this relative MSFE can be computed following the Diebold and Mariano (1994) or West (1996) procedures. However, the data requirements for these tests are high, needing a long series of predictions based on regression estimates obtained from long time series. Due to limited data availability, the simulated out-of-sample periods are rather short in this paper and we do not report standard errors for the relative MSFEs.
} 
To improve upon simple combination forecasts, two-stage combination forecasts were constructed. In addition to the combination forecast based on all the individual forecasts, we produce a combination forecast based on a selection of the best performing individual forecasts. First, we make all the individual forecasts and evaluate their performance relative to the AR benchmark over the entire sample period. Then, for each variable being forecasted, we pick the top five performers and combine them by taking the median to produce a new "second stage" combination forecast.

\section{Concurrent Forecasts}

Concurrent forecasts are useful when data are released with a considerable lag. Concurrent forecasts use indicators that are available in the current period (month, quarter etc.) to produce point estimates of economic variables that are not released until several months later. This is the case of real GDP in Turkey, which is reported with several months' lag-between two and three months. In this context, it is then useful to forecast quarterly GDP ahead of its release using indicators that are already available, i.e., to obtain concurrent forecasts of GDP.

A common approach for evaluating the predictive content of indicators for current GDP is turning point analysis. Stock and Watson (1989) produce forecasts to evaluate when the economy switches from an expansion to a contractionary phase. The results of such an analysis depend on the definition of turning point (trough or peak).

However, a problem with this approach is that the econometric techniques used require long and reliable data series with many recognizable turning points in the sample. As Simone (2001, p. 6) explains: "Even for the United States, where relatively long and comparable series are available, the number of turning points of economic activity officially recognized is relatively small. This complicates the reliability of tests of forecast accuracy given that the sample of points on which they are based is relatively small." For an emerging economy such as Turkey, this problem is compounded given the lack of relatively long time series.

An alternative method is the point predictions approach. The method compares the forecast of GDP growth made by each individual indicator with the actual ex post value. This approach, suggested in Simone (2001), avoids the large data requirements of the turning point analysis. In this paper, we follow the point predictions approach for selecting suitable coincident indicators for real GDP.

The concurrent forecasting model is a modification of the one presented above. To allow the forecasts of GDP growth in the current quarter $t$, while using current quarter data on candidate indicators, we estimate the following forecasting equation:

$$
y_{t}=\mu+\alpha(L) y_{t-1}+\beta(L) X_{t}+\varepsilon_{t}
$$

where $y_{t}$ is the growth rate of real GDP in quarter $t$ and $X_{t}$ is the current quarter value of the candidate indicator. 


\section{Results}

\section{A. Individual Indicators}

The performance of the various individual indicators relative to the AR benchmark for real GDP and for IP and the CPI is summarized below. To assess how well the AR benchmark forecasts perform relative to the actual realizations, the tables also report the root mean squared forecast error (RMSFE) of the AR forecasts.

\section{Real GDP}

- $\quad$ No indicator improves on the AR forecast of GDP for all four horizons considered (Table 2). However, some indicators improve on the AR for some horizons. The best performer at the one quarter horizon seems to be the overnight interest rate (level of "rovnght"). With a relative MSFE ratio of 0.58 , this indicator seems to provide a 42 percent improvement on the AR benchmark. At the 2 -quarter horizon, the best performer seems to be the real housing price index (level of "rlhouse"). At the 3-quarter horizon, the price earnings ratio of the Istanbul Stock Exchange (ISE) does best (level of "lpe_ise"). The IP output gap is the best performer at the 4-quarter horizon ("ip_gap_hpf").

\section{Industrial Production}

- Some variables forecast IP growth well for one or more forecast horizons (Table 3, first three columns). The best performing indicators in terms of improving on the AR seem to be the price earnings ratio of the ISE index (level of "lpe_ise"); real stock price index (first difference of "rlstockp"); the dividend yield (level of "divpr"); the commodity price index (second difference of "lcommod"), and the central bank's gross FX reserves (first difference of "lirescb"). These indicators predict output growth better than the AR benchmark for the 3, 6, and 12-month horizons.

- However, in most cases, the series that forecast IP growth well for one forecast horizon do worse than the AR benchmark at other horizons. For example, the IP growth forecast based on the nominal stock price index (first difference of "lstockp") has a relative MSFE ratio of 0.93 at the 3 -month horizon, indicating a 7 percent improvement over the AR benchmark. However, the relative MSFE is 1.0 for the 6and 12-month horizons, indicating no improvement over the AR benchmark.

\section{Consumer Price Index}

- $\quad$ Similarly, for the CPI, some variables forecast well for one or more forecast horizons (Table 3 , last 3 columns). The best performing indicators for CPI inflation 
seem to be the growth rate of the foreign exchange reserves of commercial banks (first difference of "lirescm"); the monetary aggregates (first differences of "lmon2y, Imon3, lmon3y," and "Imon2fxd"); the commodity price index (second difference of "lcommod"); gross international reserves (first difference of "lires," and of "lirgold"); and the price-earnings ratio of the Istanbul stock exchange ("lpe_ise").

- In general, the series that forecast inflation well for one horizon do worse than the AR benchmark at other horizons. The only indicators that outperform the AR benchmark inflation forecast for all three horizons are the M3Y monetary aggregate and the foreign exchange reserves of commercial banks.

\section{B. Combination Forecasts}

We next investigate whether combining the forecasts based on all the individual indicators can improve on their performance. We first consider the median of the full set of forecasts as the combination forecast. Tables 4.1 to 4.3 show the results for the combination forecasts. Reported is the MSFE of the combination forecast relative to the AR benchmark. Each table also shows the MSFE for the two-stage combination forecast.

The median forecast based on the full set of individual forecasts seems to outperform the benchmark $A R$ for both output and inflation at all horizons considered. None of the individual bivariate models that the combination forecast is based on does as well for both output and inflation. The implication of the results for economic forecasting is that one should prefer the combination forecast to any individual forecast, or indeed to a forecast with estimated weights, given the difficulties of accurately estimating them.

The two-stage combination forecasts improve on the AR benchmarks for all variables and forecasting horizons considered. The two-stage combination forecasts are based on the

five best performing individual forecasts identified in the analysis of individual indicators. For instance, the top five performers for CPI inflation were the M1 monetary aggregate (second difference of "Imonl"), the foreign exchange reserves of the central bank (level of "lirescb"), the foreign exchange reserves of commercial banks (first difference of "lirescm"), and the first and second differences of the ratio of foreign exchange deposits to the M2Y monetary aggregate. With a relative MSFE of 0.8 , the two-stage combination forecast of the CPI improves on the AR benchmark by 20 percent.

The two-stage combination forecasts appear to perform better than the combination forecasts based on the full set of bivariate forecasts. As Tables 4.1 to 4.3 suggest, the twostage forecasts based on the top five performers seem to improve on the combination forecast based on the median of all the individual indicators, i.e., the MSFEs for the two-stage combination forecasts are lower than the MSFEs for the combination forecasts based on the full set of individual predictors. This result holds for all the variables forecasted at all the horizons considered. 


\section{Concurrent Predictions of GDP}

Some indicators seem highly informative about current real GDP. The results for the individual concurrent predictions of GDP appear in Table 5. The top five indicators in terms of performing better than the AR benchmark seem to be the IP index (first difference of "lip"); the output gap ("ip_gap_hpf"); capacity utilization in the private sector ("cu_pr"), the spread between the U.S. federal funds rate and the Turkish overnight interest ("usffrrovnght"), and the Turkish overnight interest rate ("rovnght"). These indicators substantially improve on the AR. For instance, the growth rate of the IP index seems to produce a concurrent forecast that is 62 percent more accurate that the AR forecast. As indicated in Table 4.4, also in the case of concurrent GDP forecasts the median forecast based on all the individual forecasts outperforms the AR. With a relative MSFE of 0.71 , this median forecast improves on the AR benchmark by 29 percent. For the two-stage combination forecast based on the top 5 indicators, the improvement over the AR is greater at 67 percent (i.e., the relative MSFE is 0.33 ).

\section{Performance of Two-Stage Combination Forecasts over the 2000-02 Period}

In this section, we provide a graphical illustration of the recent performance of the two-stage combination forecasts. It thus complements the statistical evaluation over the entire 1992-2002 period discussed above. Two-stage combination forecasts are used to predict CPI inflation and real GDP growth for the period 2000 and 2002 (first quarter).

Real GDP growth forecasts are broadly in line with actual growth, but forecasts of CPI inflation are less accurate (Figures 3-9). ${ }^{8}$ Figure 3 shows the concurrent combination forecast-measured by the median of the forecasts obtained using the top-performing five leading indicators - - of the current-quarter real GDP growth since the end of the previous quarter. Such forecasts track the actual growth rate closely and correctly anticipate the major contraction associated with the 2001 crisis, as well as the subsequent recovery. Figures $4-6$ show actual real GDP cumulative growth over two, three, and four quarters. The figures also show the forecasts of growth made two, three, and four quarters ahead. The 2001 recession was hard to predict ahead of time, although the forecasts do predict a slowdown in economic activity. Figures 7 through 9 show the forecasts of inflation made 3,6, and 12 months ahead together with actual inflation over the same period. ${ }^{9}$ As the figures suggest, the forecast is relatively inaccurate in tracking actual inflation. In particular, the rise in inflation associated with the 2001 crisis was difficult to predict, which is, however, hardly surprising.

\footnotetext{
${ }^{8}$ The standard errors (and 95 percent confidence intervals) for these estimates are large.

${ }^{9}$ The forecasts of the level of CPI inflation are computed using the predictions of the change in the inflation rate discussed above. To each forccast of $y_{t+h}^{h}$, i.e., the forecast of $\log \left(C P I_{t+h} / C P I_{t}\right)$ - $h \log \left(C P I_{t} / C P I_{t-1}\right)$ made in month $t$, we add the actual value of $h \log \left(C P I_{t} / C P I_{t-1}\right)$. We thus obtain a forecast of $\log \left(C P I_{t+h} / C P I_{t}\right)$, i.e., of cumulative inflation over $h$ months.
} 
Figure 1. Turkey: Real GDP Growth and Growth Uncertainty, 1964-2001
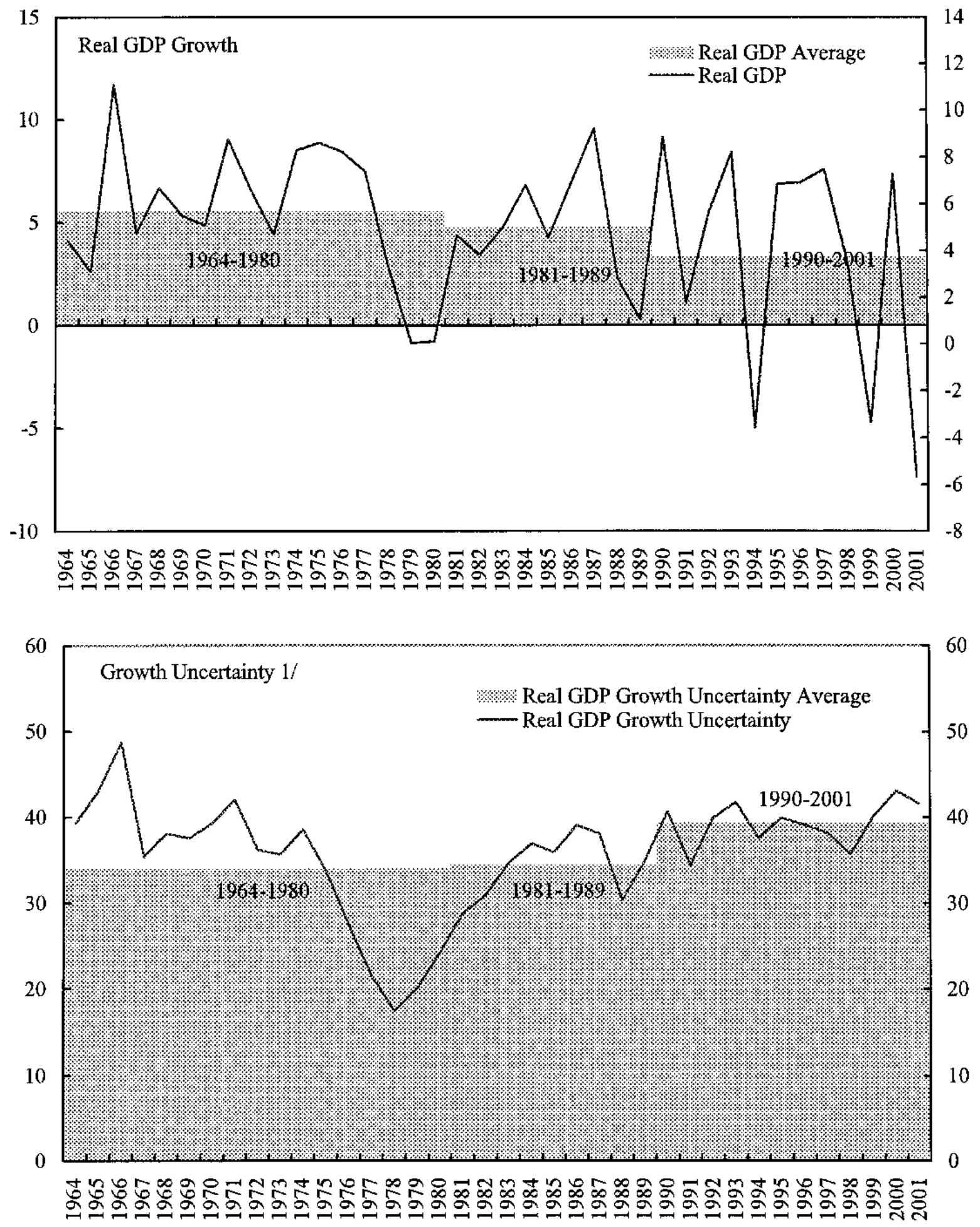

Sources: IMF, International Financial Statistics and World Economic Outlook, and IMF staff estimates.

1/ Measured by the conditional variance of GDP growth using a GARCH $(1,1)$ estimation model. 
Figure 2. Turkey: Inflation and Inflation Uncertainty 1964-2001
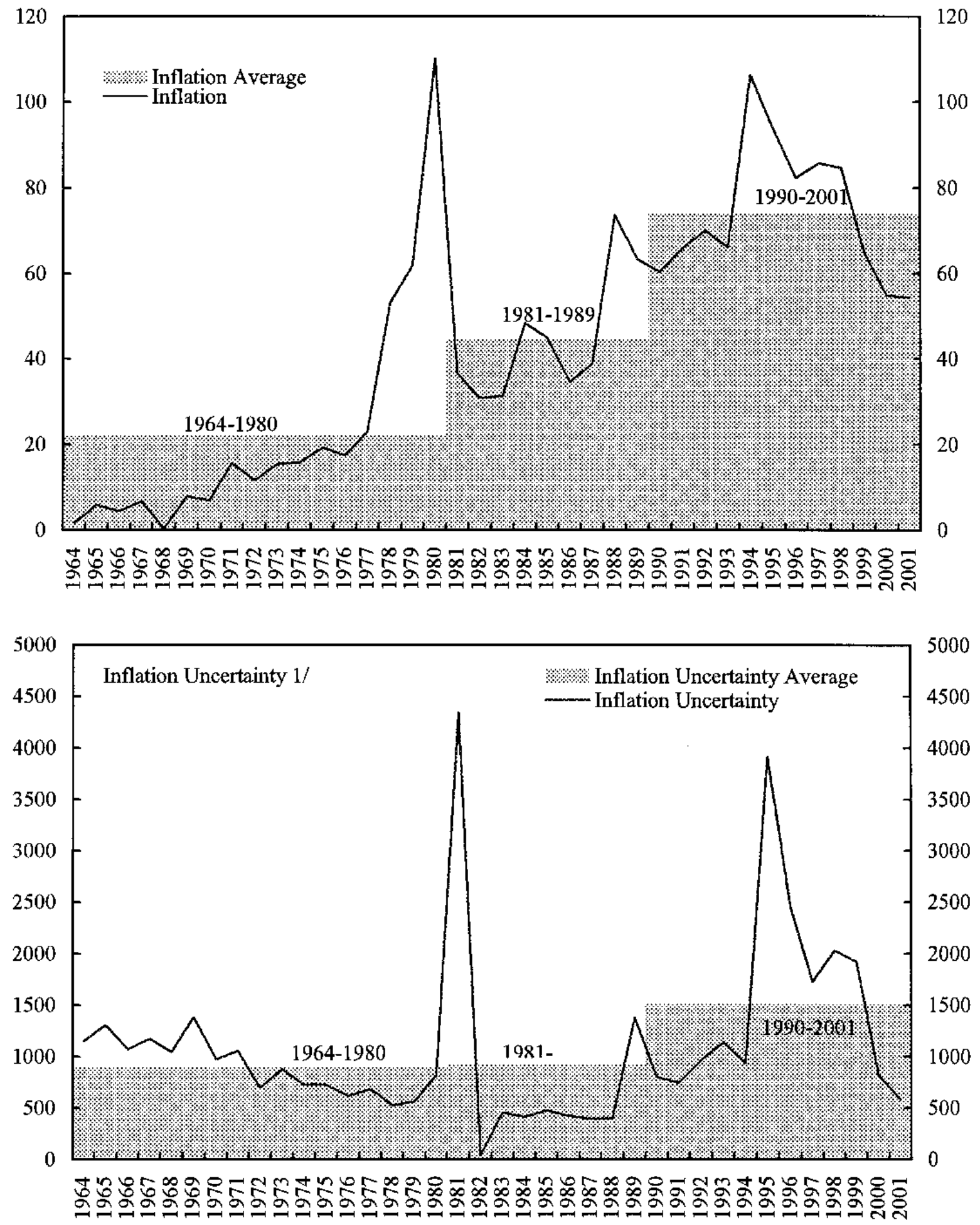

Sources: IMF, International Financial Statistics and World Economic Outlook, and IMF staff estimates.

1/ Measured by the conditional variance of CPI inflation using a GARCH $(1,1)$ estimation model. 
Table 1. Turkey: Series Descriptions and Data Sample Periods, 2001-02

\begin{tabular}{|c|c|c|c|c|c|}
\hline Series Label & Description & Start & End & Freq. & $\mathrm{SA}$ \\
\hline lgdpr & Log of Real Gross Domestic Product & 1987.1 & 2002.1 & $\mathrm{Q}$ & SA \\
\hline lip & Log of Index of Industrial Production & 1986.02 & 2002.04 & $\mathrm{M} \& \mathrm{Q}$ & SA \\
\hline ip_gap_hpf & Ouput Gap of Industrial Production & 1986.01 & 2002.04 & $M \& Q$ & SA \\
\hline cu_p & Capacity Utilization in the Public Sector & 1986.01 & 2002.06 & $Q$ & $\mathrm{SA}$ \\
\hline cu_pr & Capacity Utilization in the Private Sector & 1986.01 & 2002.06 & $\mathrm{Q}$ & SA \\
\hline lcpi & Log of Consumer Price Index & 1986.02 & 2002.06 & $M \& Q$ & SA \\
\hline lppi & Log of Producer Price Index & 1987.02 & 2002.05 & $M \& Q$ & SA \\
\hline lwpi & Log of Wholesale Price Index & 1986.02 & 2002.06 & $M \& Q$ & SA \\
\hline loil & Log of Oil Price & 1986.02 & 2002.04 & $M \& Q$ & NSA \\
\hline rloil & Log of Real Oil Price & 1986.02 & 2002.03 & $M \& Q$ & NSA \\
\hline lcommod & Log of Commodity Price Index & 1986.02 & 2002.04 & $\mathrm{M} \& \mathrm{Q}$ & NSA \\
\hline rlcomod & Log of Real Commodity Price index & 1986.02 & 2002.03 & $\mathrm{M} \& \mathrm{Q}$ & NSA \\
\hline lmon1 & Log of Money: M1 & 1986.02 & 2002.04 & $M \& Q$ & $\mathrm{SA}$ \\
\hline lmon2 & Log of Money: M2 & 1986.02 & 2002.04 & $\mathrm{M} \& \mathrm{Q}$ & SA \\
\hline $\operatorname{lmon} 2 y$ & Log of Money: M2Y & 1986.02 & 2002.04 & $\mathrm{M} \& \mathrm{Q}$ & SA \\
\hline $\operatorname{lmon} 3$ & Log of Money: M3 & 1986.02 & 2002.04 & $\mathrm{M} \& \mathrm{Q}$ & SA \\
\hline $1 \operatorname{mon} 3 y$ & Log of Money: M3Y & 1986.02 & 2002.04 & $\mathrm{M} \& \mathrm{Q}$ & SA \\
\hline lresm & Log of Reserve Money & 1986.02 & 2002.04 & $\mathrm{M} \& \mathrm{Q}$ & SA \\
\hline rlmon1 & Log of Real Money: M1 & 1986.02 & 2002.04 & M\&Q & SA \\
\hline rlmon2 & Log of Real Money: M2 & 1986.02 & 2002.04 & $\mathrm{M} \& \mathrm{Q}$ & SA \\
\hline rlmon2y & Log of Real Money: M2Y & 1986.02 & 2002.04 & $\mathrm{M} \& \mathrm{Q}$ & SA \\
\hline rlmon3 & Log of Real Money: M3 & 1986.02 & 2002.04 & $\mathrm{M} \& \mathrm{Q}$ & SA \\
\hline rlmon3y & Log of Real Money: M3Y & 1986.02 & 2002.04 & $M \& Q$ & SA \\
\hline rlresm & Log of Real Reserve Money & 1986.02 & 2002.04 & $M \& Q$ & SA \\
\hline lfxdnb & Log of Residents FX Deposits & 1986.01 & 2002.04 & $M \& Q$ & SA \\
\hline $\mathrm{m} 2 \mathrm{y}$ fxd & Log of Money: M2Y + Residents' FX Deposits & 1986.01 & 2002.04 & $M \& Q$ & SA \\
\hline rovnght & Interest Rate-Overnight & 1986.04 & 2002.03 & $M \& Q$ & NSA \\
\hline rdiscount & Interest Rate- Discount & 1986.01 & 2002.04 & M\&Q & NSA \\
\hline rtime_3mth & Interest Rate -3 Month Deposit & 1986.01 & 2002.03 & $\mathrm{M} \& \mathrm{Q}$ & NSA \\
\hline lexrate & Log of Nominal (TL/\$) Exchange Rate & 1986.02 & 2002.05 & M\&Q & NSA \\
\hline lrexrate & Log of Real Effective Exchange Rate & 1986.02 & 2002.05 & $\mathrm{M} \& \mathrm{Q}$ & NSA \\
\hline 1stockp & Log of Stock Price Index & 1986.02 & 2001.11 & $\mathrm{M} \& \mathrm{Q}$ & NSA \\
\hline rlstockp & Log of Real Stock Price Index & 1986.02 & 2001.11 & $\mathrm{M} \& \mathrm{Q}$ & NSA \\
\hline pe_ise & Log of Price Earnings Ratio of Istanbul Stock Exch. & 1986.01 & 2001.10 & $\mathrm{M} \& \mathrm{Q}$ & NSA \\
\hline divpr & Dividend Yield & 1986.01 & 2001.10 & $\mathrm{M} \& \mathrm{Q}$ & NSA \\
\hline lhouse & Log of House Price Index & 1987.02 & 2002.01 & $M \& Q$ & SA \\
\hline rlhouse & Log of Real House Price Index & 1987.01 & 2002.01 & $M \& Q$ & SA \\
\hline lgold & Log of Gold Price & 1986.02 & 2002.04 & M\&Q & NSA \\
\hline us_ffr_rovnght & Spread - U.S. Fed Funds-rovnght & 1986.04 & 2002.03 & M\&Q & NSA \\
\hline loverdraft & Log of Overdrafts & 1986.01 & 2001.10 & $M \& Q$ & NSA \\
\hline lirescb & Log of Central Bank's Gross FX Reserves & 1986.01 & 2001.10 & $\mathrm{M} \& \mathrm{Q}$ & NSA \\
\hline lirescm & Log of Commercial Banks' Gross FX Reserves & 1986.01 & 2001.10 & $M \& Q$ & NSA \\
\hline lircbcm & Log of Ratio of Central to Comm. Banks' FX Rescrves & 1986.01 & 2001.10 & $\mathrm{M} \& \mathrm{Q}$ & NSA \\
\hline lires_gold & Log of Gross International Reserves: Gold & 1986.01 & 2001.10 & $\mathrm{M} \& \mathrm{Q}$ & NSA \\
\hline lires & Log of Gross International Reserves & 1986.01 & 2001.10 & $\mathrm{M} \& \mathrm{Q}$ & NSA \\
\hline
\end{tabular}

Sources: State Institute of Statistics, and Central Bank of Turkey. 
Table 2. Real GDP Growth Out-Of-Sample Forecasting Results, 1992-2002

\begin{tabular}{|c|c|c|c|c|c|}
\hline \multicolumn{2}{|c|}{ Forecast Horizon } & $\mathrm{h}=1$ & $\mathbf{h}=2$ & $\mathrm{~h}=3$ & $h=4$ \\
\hline \multirow{2}{*}{\multicolumn{2}{|c|}{ Univariate Autorcgression }} & \multicolumn{4}{|c|}{ Root Mean Square Forceast Error } \\
\hline & & 3.69 & 5.19 & 6.18 & 6.92 \\
\hline \multicolumn{2}{|c|}{ Bivariate Forecasts } & \multicolumn{4}{|c|}{ MSFE Relative to Univariate Autoregression } \\
\hline Indicator & Transformation & & & & \\
\hline lcpi & d & 2.67 & 1.33 & 2.11 & 1.30 \\
\hline lppi & $\mathrm{d}$ & 2.61 & 1.55 & 1.39 & 1.44 \\
\hline lwpi & $d$ & 2.23 & 1.83 & 1.35 & 1.20 \\
\hline loil & $\mathrm{d}$ & 1.66 & 1.61 & 1.22 & 1.46 \\
\hline rloil & $\mathrm{d}$ & 1.33 & 1.34 & 1.21 & 1.43 \\
\hline lcommod & $\mathrm{d}$ & 1.77 & 1.30 & 1.11 & 1.15 \\
\hline rlcomod & $d$ & 1.41 & 1.29 & 1.34 & 1.34 \\
\hline lcpi & $2 \mathrm{~d}$ & 1.73 & 1.02 & 1.48 & 1.06 \\
\hline 1ppi & $2 d$ & 1.91 & 1.22 & 1.10 & 1.46 \\
\hline lwpi & $2 \mathrm{~d}$ & 1.49 & 1.20 & 1.08 & 1.01 \\
\hline loil & $2 d$ & 1.18 & 1.18 & 0.99 & 1.13 \\
\hline lcommod & $2 d$ & 1.57 & 1.21 & 1.06 & 1.17 \\
\hline lmon1 & $\mathrm{d}$ & 1.02 & 1.02 & 1.05 & 1.15 \\
\hline $\operatorname{lmon} 2$ & d & 1.87 & 1.71 & 1.81 & 1.78 \\
\hline $\operatorname{lmon} 2 y$ & $\mathrm{~d}$ & 1.92 & 2.15 & 1.93 & 1.99 \\
\hline lmon3 & d & 1.81 & 1.76 & 1.95 & 2.11 \\
\hline Imon3y & d & 1.90 & 2.10 & 1.79 & 1.79 \\
\hline 1resm & $\mathrm{d}$ & 1.51 & 1.21 & 1.05 & 1.07 \\
\hline 1monl & $2 \mathrm{~d}$ & 1.09 & 0.97 & 1.06 & 1.12 \\
\hline $1 m o n 2 y$ & $2 \mathrm{~d}$ & 1.72 & 1.75 & 1.60 & 1.57 \\
\hline 1mon3 & $2 \mathrm{~d}$ & 2.01 & 1.53 & 1.85 & 1.28 \\
\hline $1 \mathrm{mon} 3 \mathrm{y}$ & $2 \mathrm{~d}$ & 1.66 & 1.66 & 1.57 & 1.53 \\
\hline 1resm & $2 \mathrm{~d}$ & 1.52 & 1.21 & 1.21 & 1.13 \\
\hline rlmon1 & d & 1.09 & 1.13 & 1.29 & 1.27 \\
\hline rlmon2 & $\mathrm{d}$ & 1.58 & 1.28 & 1.34 & 1.18 \\
\hline rlmon2y & $\mathrm{d}$ & 1.31 & 1.31 & 1.19 & 1.21 \\
\hline rlmon3 & $\mathrm{d}$ & 1.67 & 1.26 & 1.34 & 1.12 \\
\hline rlmon3y & d & 1.35 & 1.37 & 1.14 & 1.19 \\
\hline rlresm & d & 1.26 & 1.14 & 1.14 & 1.09 \\
\hline rovnght & level & 0.58 & 1.07 & 1.30 & 1.11 \\
\hline rdiscount & level & 1.73 & 1.37 & 1.26 & 1.06 \\
\hline rtime_3mth & level & 1.77 & 1.69 & 1.64 & 1.44 \\
\hline rovnght & d & 0.91 & 1.06 & 1.36 & 1.22 \\
\hline rdiscount & d & 1.34 & 1.00 & 1.16 & 1.05 \\
\hline rtime_3mth & $d$ & 1.44 & 1.57 & 1.73 & 1.34 \\
\hline lexrate & d & 1.79 & 1.29 & 1.36 & 1.21 \\
\hline Irexrate & d & 1.45 & 1.48 & 1.70 & 1.57 \\
\hline 1stockp & d & 0.94 & 1.06 & 1.08 & 1.15 \\
\hline rlstockp & d & 0.93 & 1.06 & 1.16 & 1.14 \\
\hline divpr & level & 1.03 & 1.06 & 0.98 & 1.04 \\
\hline divpr & $\mathrm{d}$ & 1.04 & 1.13 & 1.20 & 1.16 \\
\hline lhouse & d & 1.19 & 1.20 & 1.18 & 1.24 \\
\hline rlhouse & 1evel & 1.28 & 0.88 & 1.02 & 1.03 \\
\hline rlhouse & $\mathrm{d}$ & 1.13 & 0.96 & 1.11 & 1.22 \\
\hline
\end{tabular}


Table 2. Real GDP Growth Out-Of-Sample Forecasting Results, 1992-2002

\begin{tabular}{|c|c|c|c|c|c|}
\hline \multicolumn{2}{|c|}{ Forecast Horizon } & $\mathrm{h}=1$ & $\mathrm{~h}=2$ & $h=3$ & $h=4$ \\
\hline \multicolumn{2}{|c|}{ Univariate Autoregression } & \multicolumn{4}{|c|}{ Root Mean Squarc Forecast Error } \\
\hline & & 3.69 & 5.19 & 6.18 & 6.92 \\
\hline \multicolumn{2}{|c|}{ Bivariate Forecasts } & \multicolumn{4}{|c|}{ MSFE Relative to Univariate Autoregression } \\
\hline Indicator & Transformation & & & & \\
\hline lgold & $\mathrm{d}$ & 1.84 & 1.55 & 1.46 & 1.23 \\
\hline lgold & $2 \mathrm{~d}$ & 1.61 & 1.18 & 1.36 & 1.20 \\
\hline rlgold & $\mathrm{d}$ & 2.10 & 1.71 & 1.50 & 1.26 \\
\hline rlgold & $2 \mathrm{~d}$ & 1.84 & 1.50 & 1.50 & 1.32 \\
\hline usffrrovnght & level & 0.61 & 1.08 & 1.29 & 1.11 \\
\hline lover & level & 1.36 & 1.11 & 1.19 & 1.18 \\
\hline lover & d & 1.17 & 1.04 & 1.02 & 1.12 \\
\hline lirescb & level & 1.01 & 1.14 & 1.21 & 1.37 \\
\hline lirescb & $\mathrm{d}$ & 0.93 & 1.01 & 1.09 & 1.17 \\
\hline lirescm & level & 1.36 & 1.25 & 1.30 & 1.72 \\
\hline lirescm & $\mathrm{d}$ & 1.21 & 1.14 & 1.16 & 1.13 \\
\hline lirebcm & level & 1.04 & 1.06 & 1.25 & 1.45 \\
\hline lircbem & $\mathrm{d}$ & 1.09 & 1.04 & 1.10 & 1.12 \\
\hline lfxdnb & level & 3.50 & 3.63 & 2.86 & 2.65 \\
\hline 1fxdnb & $\mathrm{d}$ & 3.27 & 3.29 & 2.70 & 2.37 \\
\hline lirgold & level & 1.25 & 1.45 & 1.92 & 2.23 \\
\hline lirgold & d & 1.22 & 1.27 & 1.39 & 1.48 \\
\hline lires & level & 1.07 & 1.25 & 1.27 & 1.44 \\
\hline lires & d & 0.99 & 1.13 & 1.12 & 1.22 \\
\hline $\operatorname{lmon} 2 \mathrm{fxd}$ & $d$ & 1.27 & 1.18 & 1.24 & 1.25 \\
\hline $\operatorname{lmon} 2 \mathrm{f} x \mathrm{~d}$ & $2 \mathrm{~d}$ & 1.27 & 1.17 & 1.26 & 1.13 \\
\hline lpe_ise & level & 0.86 & 1.02 & 0.95 & 1.09 \\
\hline 1pe_ise & d & 0.88 & 1.14 & 1.24 & 1.21 \\
\hline $\mathrm{cu}_{-} \mathrm{p}$ & level & 1.15 & 1.05 & 1.14 & 1.30 \\
\hline cu_pr & level & 1.37 & 1.47 & 1.46 & 1.36 \\
\hline ip_gap_hpf & level & 1.30 & 1.13 & 1.06 & 0.83 \\
\hline lip & $\mathrm{d}$ & 1.32 & 1.15 & 1.10 & 1.01 \\
\hline
\end{tabular}

Sources: State Institute of Statistics, and Central Bank of Turkey. 
Table 3. Industrial Production and CPI Inflation Out-Of-Sample Forecasting Results, 1992-2002

\begin{tabular}{|c|c|c|c|c|c|c|c|}
\hline \multirow{3}{*}{\multicolumn{2}{|c|}{$\begin{array}{l}\text { Forecast Horizon } \\
\text { Univ. Autoregression }\end{array}$}} & \multicolumn{3}{|c|}{ Industrial Production } & \multicolumn{3}{|c|}{ CPI Inflation } \\
\hline & & $\mathrm{h}=3$ & $h=6$ & $\mathrm{~h}=12$ & $\mathrm{~h}=3$ & $\mathrm{~h}=6$ & $\mathrm{~h}=12$ \\
\hline & & \multicolumn{6}{|c|}{ Root Mean Square Forecast Error } \\
\hline & & 5.91 & 7.01 & 9.41 & 5.55 & 8.61 & 14.54 \\
\hline \multicolumn{2}{|c|}{ Bivariate Forecasts } & \multicolumn{6}{|c|}{ MSFE Relative to Univariate Autoregression } \\
\hline Indicator & Transfor. & & & & & & \\
\hline $\operatorname{lip}$ & $\mathrm{d}$ & & & & 1.23 & 1.09 & 1.10 \\
\hline ip_gap_hpf & level & & & & 0.98 & 1.20 & 1.37 \\
\hline lcpi & $\mathrm{d}$ & 1.11 & 1.03 & 0.99 & & & \\
\hline lppi & $\mathrm{d}$ & 1.85 & 1.51 & 1.00 & 2.17 & 1.17 & 1.04 \\
\hline lwpi & $d$ & 1.35 & 1.07 & 0.95 & 1.01 & 0.97 & 1.02 \\
\hline loil & $d$ & 1.28 & 1.06 & 1.29 & 1.11 & 1.15 & 1.22 \\
\hline rloil & $\mathrm{d}$ & 1.06 & 1.02 & 1.25 & 1.10 & 1.24 & 1.28 \\
\hline lcommod & $\mathrm{d}$ & 1.46 & 1.05 & 1.22 & 1.39 & 1.18 & 1.03 \\
\hline rlcomod & $\mathrm{d}$ & 0.97 & 1.06 & 1.28 & 1.06 & 1.17 & 1.11 \\
\hline lcpi & $2 d$ & 0.97 & 1.04 & 1.02 & & & \\
\hline lppi & $2 d$ & 1.78 & 1.62 & 1.07 & 1.69 & 1.32 & 1.54 \\
\hline lwpi & $2 \mathrm{~d}$ & 1.08 & 1.10 & 1.00 & 1.03 & 1.15 & 1.06 \\
\hline loil & $2 d$ & 1.39 & 0.99 & 0.96 & 1.03 & 1.06 & 1.12 \\
\hline lcommod & $2 d$ & 1.46 & 0.98 & 0.97 & 0.96 & 0.98 & 1.17 \\
\hline lmon 1 & $\mathrm{~d}$ & 1.12 & 1.04 & 1.01 & 0.96 & 1.21 & 1.34 \\
\hline $\operatorname{lmon} 2$ & $\mathrm{~d}$ & 1.10 & 1.25 & 1.11 & 1.25 & 1.11 & 1.10 \\
\hline $\operatorname{lmon} 2 y$ & d & 1.19 & 1.05 & 0.98 & 1.05 & 0.92 & 0.93 \\
\hline $\operatorname{lmon} 3$ & $d$ & 1.10 & 1.09 & 1.07 & 1.32 & 0.98 & 0.99 \\
\hline 1mon3y & $d$ & 1.12 & 1.05 & 1.03 & 0.99 & 0.92 & 0.88 \\
\hline lresm & $\mathrm{d}$ & 1.30 & 1.13 & 0.99 & 1.01 & 0.90 & 1.32 \\
\hline lmon 1 & $2 d$ & 1.08 & 1.07 & 1.01 & 0.93 & 1.10 & 1.17 \\
\hline $\operatorname{lmon} 2 y$ & $2 d$ & 1.17 & 1.13 & 1.00 & 1.25 & 1.09 & 1.21 \\
\hline $\operatorname{lmon} 3$ & $2 d$ & 1.14 & 1.04 & 1.12 & 1.68 & 1.48 & 1.25 \\
\hline $\operatorname{lmon} 3 y$ & $2 d$ & 1.03 & 1.08 & 1.03 & 1.20 & 1.23 & 1.03 \\
\hline lresm & $2 d$ & 1.12 & 1.05 & 0.98 & 1.16 & 1.09 & 1.26 \\
\hline rlmon 1 & $\mathrm{~d}$ & 0.98 & 1.27 & 1.11 & 1.01 & 1.00 & 1.00 \\
\hline rlmon2 & d & 1.12 & 1.16 & 1.14 & 1.29 & 1.46 & 1.37 \\
\hline $\operatorname{rlmon} 2 y$ & d & 1.24 & 1.02 & 1.05 & 1.11 & 1.03 & 1.27 \\
\hline rlmon3 & $\mathrm{d}$ & 1.11 & 1.13 & 1.06 & 1.29 & 1.35 & 1.23 \\
\hline $\operatorname{rlmon} 3 y$ & d & 1.19 & 0.97 & 1.03 & 1.10 & 1.11 & 1.00 \\
\hline rlresm & $\mathrm{d}$ & 1.08 & 1.08 & 0.96 & 0.99 & 1.20 & 1.32 \\
\hline rovnght & level & 1.22 & 1.19 & 1.06 & 1.25 & 1.23 & 1.44 \\
\hline rdiscount & level & 1.28 & 1.20 & 1.28 & 1.16 & 1.02 & 0.90 \\
\hline rtime_3mth & level & 1.92 & 1.06 & 1.19 & 2.27 & 1.58 & 1.78 \\
\hline rovnght & $\mathrm{d}$ & 1.78 & 1.22 & 1.02 & 1.53 & 1.12 & 1.27 \\
\hline rdiscount & $\mathrm{d}$ & 1.34 & 1.13 & 1.10 & 1.15 & 1.08 & 0.96 \\
\hline rtime_3mth & $\mathrm{d}$ & 1.97 & 1.08 & 1.04 & 2.12 & 1.42 & 1.28 \\
\hline lexrate & $\mathrm{d}$ & 1.36 & 1.04 & 1.08 & 2.53 & 1.04 & 1.05 \\
\hline lrexrate & $\mathrm{d}$ & 1.22 & 0.99 & 0.98 & 2.81 & 1.07 & 1.20 \\
\hline lstockp & $\mathrm{d}$ & 0.93 & 1.00 & 1.00 & 1.23 & 1.10 & 1.42 \\
\hline rlstockp & $\mathrm{d}$ & 0.91 & 0.99 & 0.99 & 1.15 & 1.24 & 1.32 \\
\hline divpr & level & 1.02 & 0.99 & 0.95 & 1.16 & 1.10 & 1.06 \\
\hline
\end{tabular}


Table 3. Industrial Production and CPI Inflation Out-Of-Sample Forecasting Results, 1992-2002

\begin{tabular}{|c|c|c|c|c|c|c|c|}
\hline \multirow{3}{*}{\multicolumn{2}{|c|}{$\begin{array}{l}\text { Forecast Horizon } \\
\text { Univ. Autoregression }\end{array}$}} & \multicolumn{3}{|c|}{ Industrial Production } & \multicolumn{3}{|c|}{ CPI Inflation } \\
\hline & & $\mathrm{h}=3$ & $\mathrm{~h}=6$ & & & $h=6$ & $\mathrm{~h}=12$ \\
\hline & & \multicolumn{6}{|c|}{ Root Mean Square Forecast Error } \\
\hline & & 5.91 & 7.01 & 9.41 & 5.55 & 8.61 & 14.54 \\
\hline \multicolumn{2}{|c|}{ Bivariate Forecasts } & \multicolumn{6}{|c|}{ MSFE Relative to Univariate Autoregression } \\
\hline Indicator & Transfor. & & & & & & \\
\hline divpr & d & 1.03 & 0.97 & 1.05 & 1.14 & 1.19 & 1.04 \\
\hline lhouse & $\mathrm{d}$ & 1.04 & 1.01 & 1.02 & 1.18 & 1.12 & 1.10 \\
\hline rlhousc & level & 1.10 & 1.09 & 1.05 & 1.07 & 1.17 & 1.51 \\
\hline rlhouse & $\mathrm{d}$ & 1.11 & 1.01 & 0.97 & 1.03 & 0.98 & 1.11 \\
\hline lgold & $\mathrm{d}$ & 1.27 & 1.10 & 1.25 & 1.45 & 1.26 & 1.25 \\
\hline lgold & $2 \mathrm{~d}$ & 1.11 & 1.03 & 1.05 & 1.24 & 1.14 & 1.18 \\
\hline rlgold & $\mathrm{d}$ & 1.03 & 1.10 & 1.35 & 1.85 & 1.48 & 1.23 \\
\hline rlgold & $2 d$ & 1.24 & 0.99 & 1.02 & 1.39 & 1.30 & 1.25 \\
\hline usffrrovnght & level & 1.22 & 1.18 & 1.09 & 1.23 & 1.26 & 1.54 \\
\hline lover & level & 1.01 & 1.01 & 1.07 & 1.05 & 1.03 & 1.34 \\
\hline lover & $\mathrm{d}$ & 1.04 & 0.99 & 1.02 & 1.02 & 0.98 & 1.28 \\
\hline lirescb & level & 0.94 & 1.02 & 1.05 & 0.91 & 1.00 & 1.20 \\
\hline lirescb & $\mathrm{d}$ & 0.93 & 0.99 & 0.97 & 1.00 & 0.95 & 1.26 \\
\hline lirescm & level & 0.96 & 1.17 & 1.25 & 1.01 & 1.22 & 1.65 \\
\hline lirescm & $\mathrm{d}$ & 0.94 & 1.00 & 1.05 & 0.88 & 0.98 & 0.99 \\
\hline lircbcm & level & 0.90 & 1.02 & 1.31 & 1.00 & 1.02 & 1.19 \\
\hline lircbem & $\mathrm{d}$ & 0.89 & 1.01 & 0.98 & 0.94 & 0.94 & 1.20 \\
\hline lfxdnb & level & 0.95 & 1.02 & 1.72 & 1.88 & 1.37 & 2.67 \\
\hline lfxdnb & $\mathrm{d}$ & 1.00 & 1.04 & 1.10 & 1.87 & 1.42 & 2.48 \\
\hline lirgold & level & 1.01 & 1.23 & 1.63 & 1.02 & 1.18 & 1.48 \\
\hline lirgold & $\mathrm{d}$ & 0.93 & 0.99 & 1.10 & 0.94 & 0.93 & 1.14 \\
\hline lires & level & 0.91 & 1.00 & 1.08 & 0.94 & 0.96 & 1.19 \\
\hline lires & $\mathrm{d}$ & 0.92 & 1.01 & 1.07 & 0.93 & 0.94 & 1.06 \\
\hline $\operatorname{lmon} 2 \mathrm{fxd}$ & $\mathrm{d}$ & 1.05 & 1.02 & 1.02 & 0.92 & 0.89 & 1.08 \\
\hline $\operatorname{lmon} 2 \mathrm{fxd}$ & $2 d$ & 1.01 & 1.05 & 1.01 & 0.87 & 0.92 & 1.18 \\
\hline lpe_ise & level & 0.90 & 0.98 & 0.83 & 0.96 & 1.04 & 1.07 \\
\hline lpe ise & $\mathrm{d}$ & 0.94 & 1.02 & 0.99 & 0.95 & 1.02 & 1.18 \\
\hline
\end{tabular}

Sources: State Institute of Statistics, and Central Bank of Turkey. 


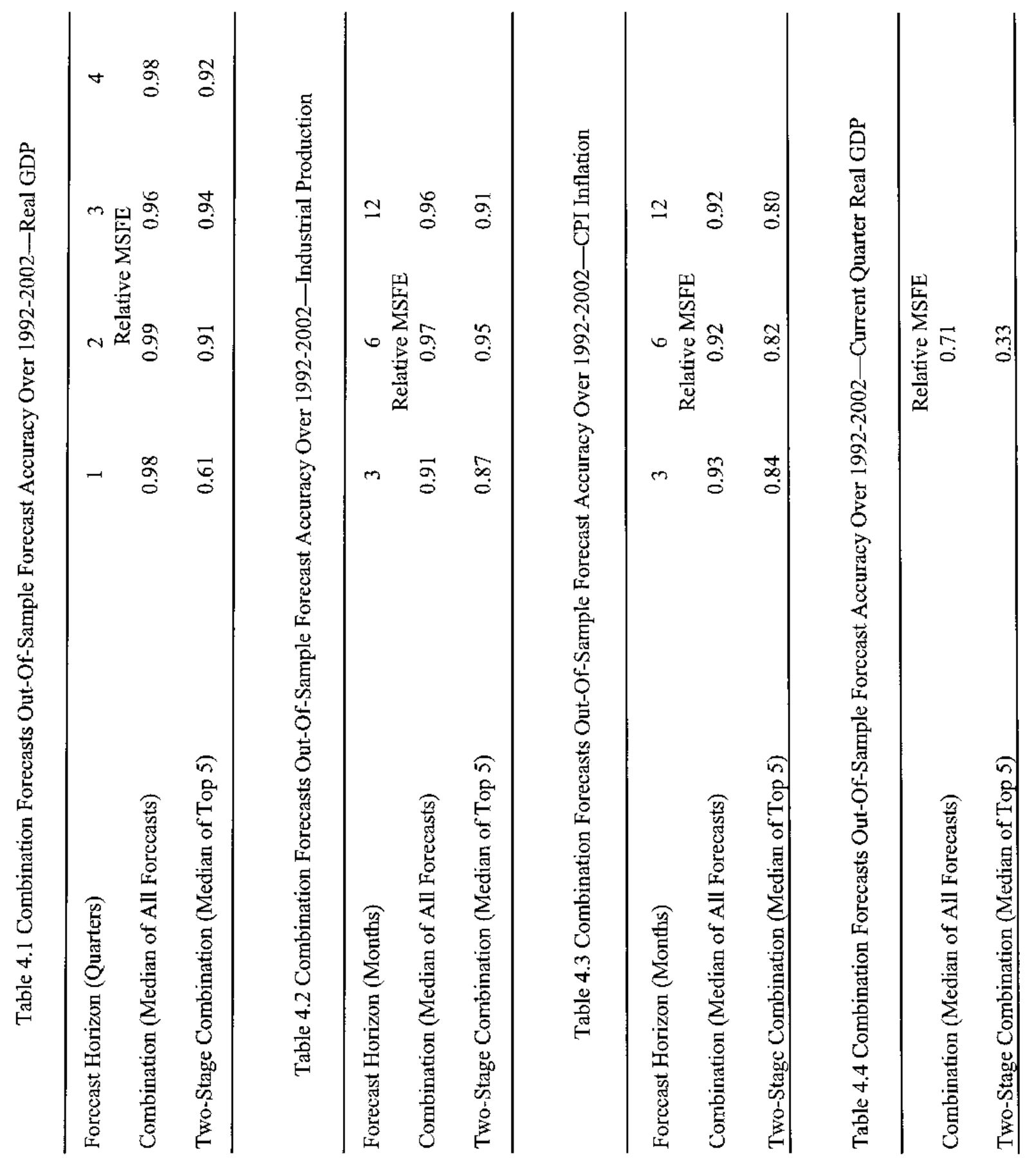


Table 5. Current Quarter Real GDP Growth

Out-Of-Sample Forecasting Results, 1992-2002

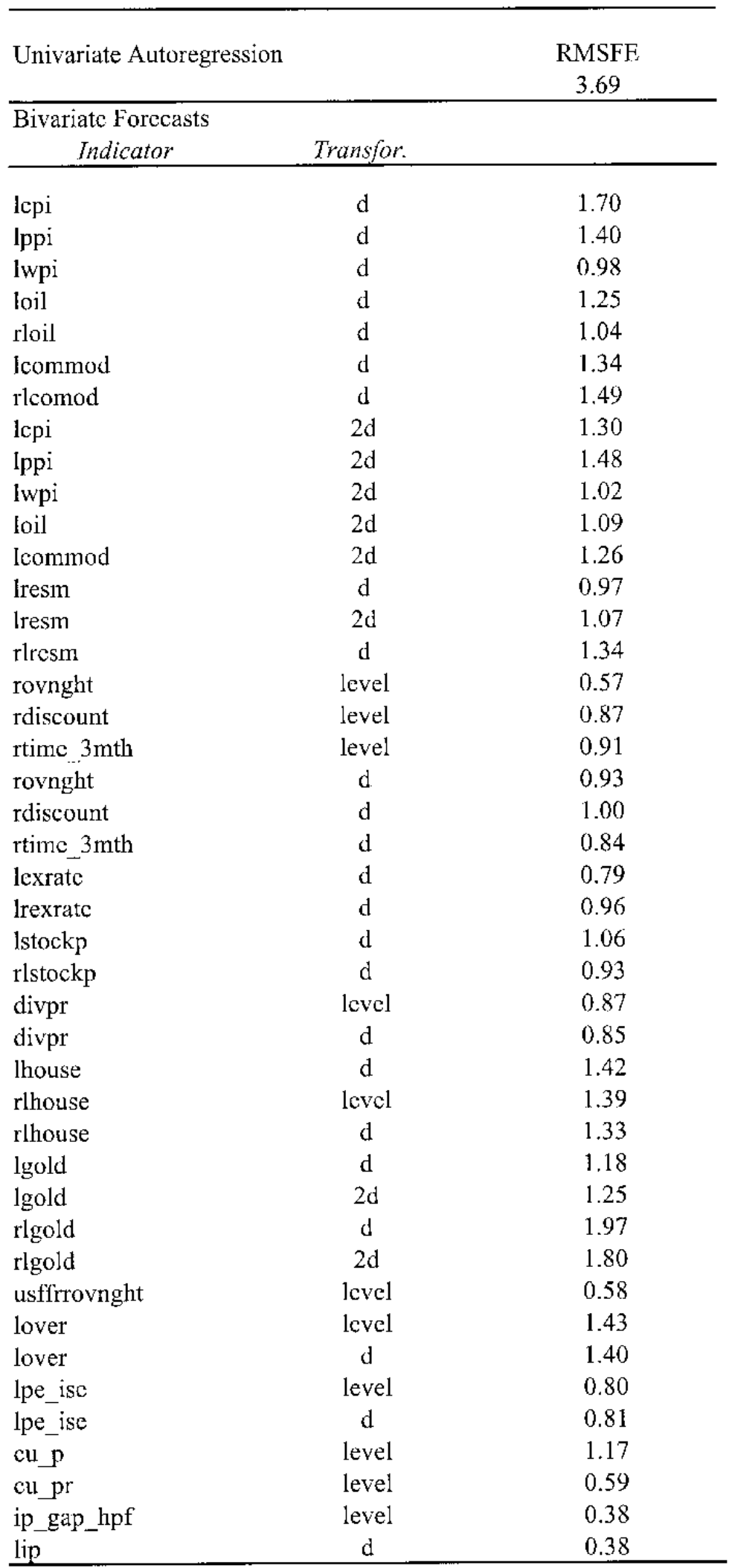


FIGURE 3. Growth Over THE CURRENT QuARTER (Seasonally Adjusted)

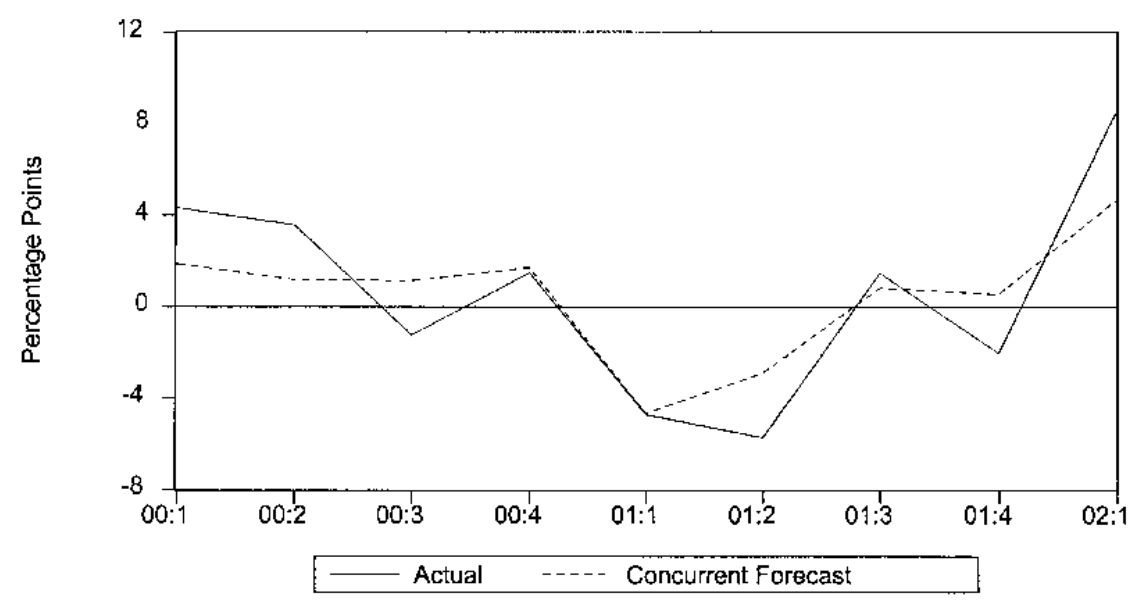

Figure 4. Cumulative Growth Over Two Quarters (Seasonally Adjusted)

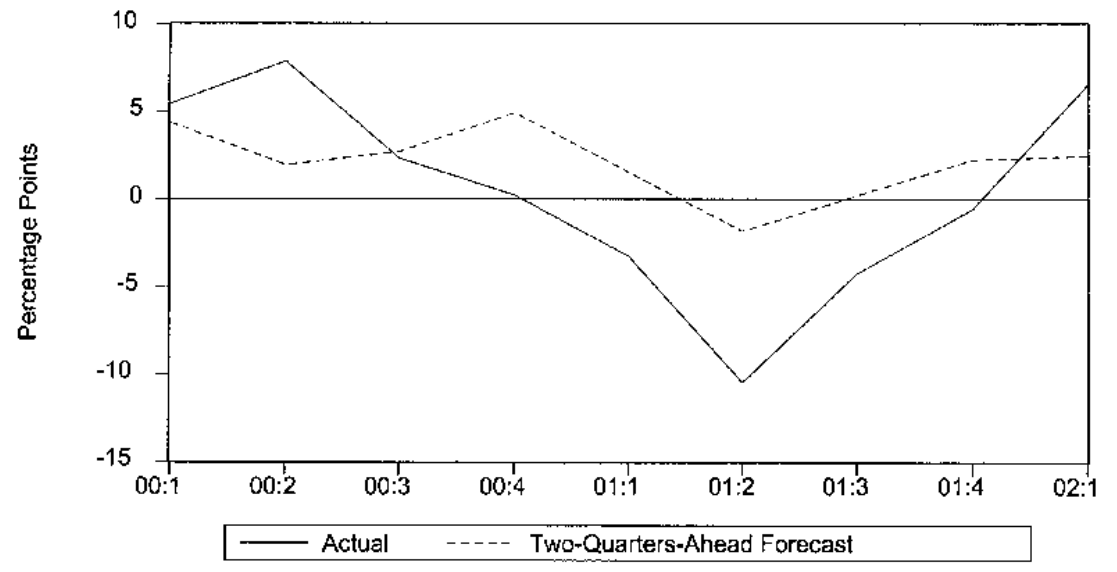


Figure 5. Cumulative Growth OVer Three Quarters (Seasonally Adjusted)

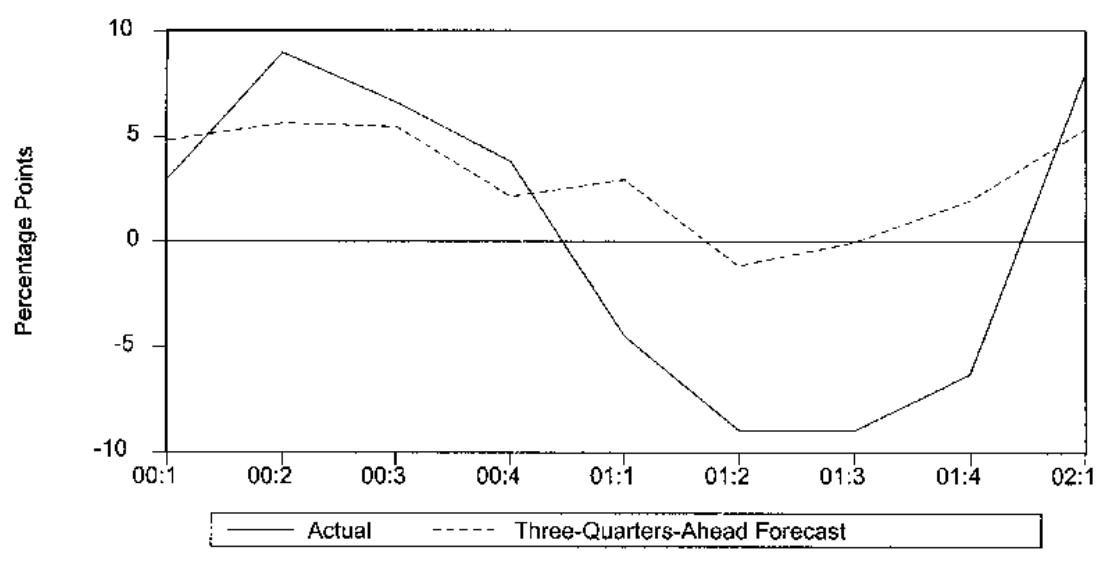

Figure 6. Cumulative Growth Over Four Quarters (Seasonally Adjusted)

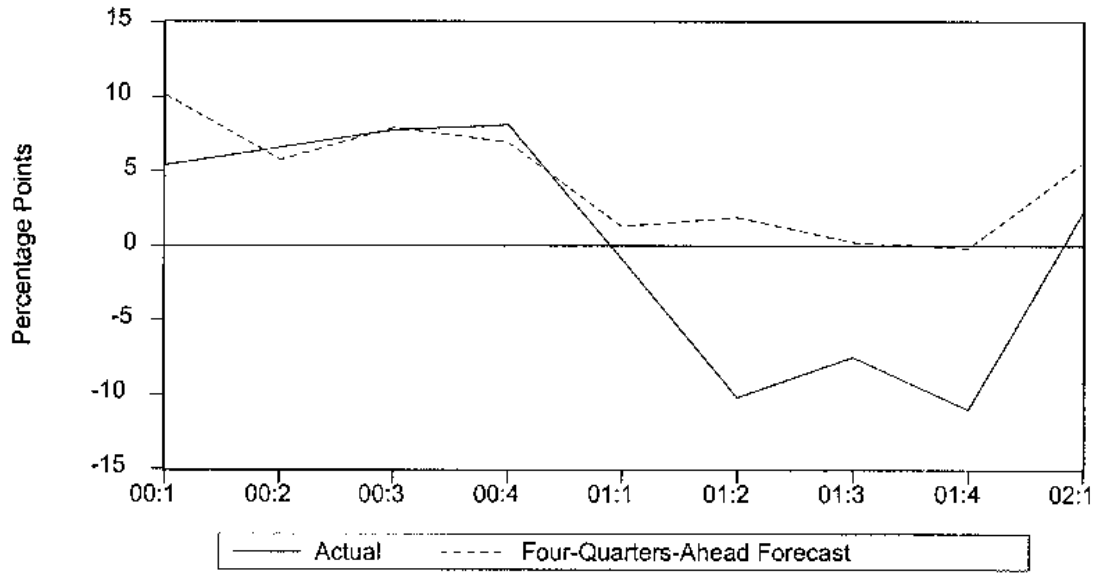


Figure 7. Cumulative Inflation Over Three Months (Seasonally Adjusted)

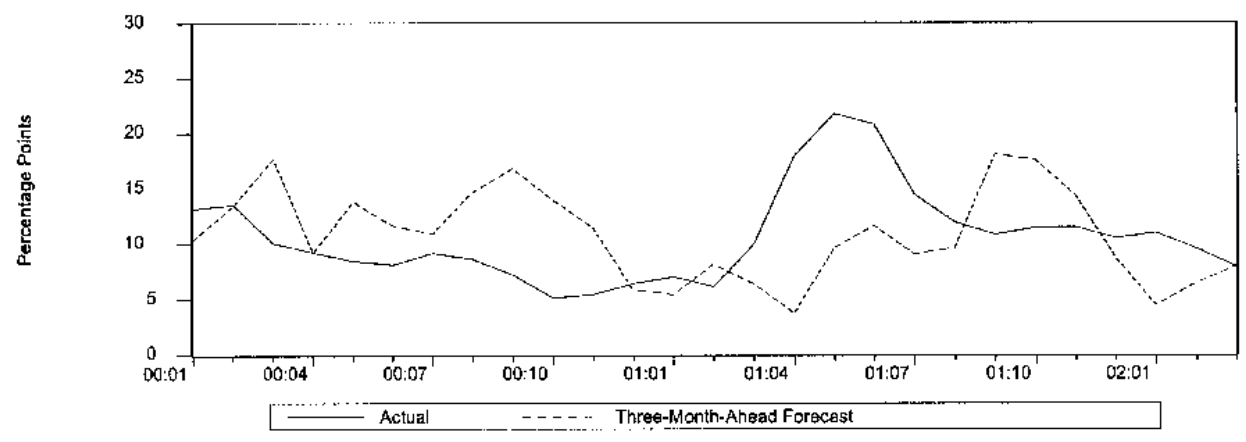

Figure 8. Cumulative Inflation OVER Six MONTHS (Seasonally Adjusted)

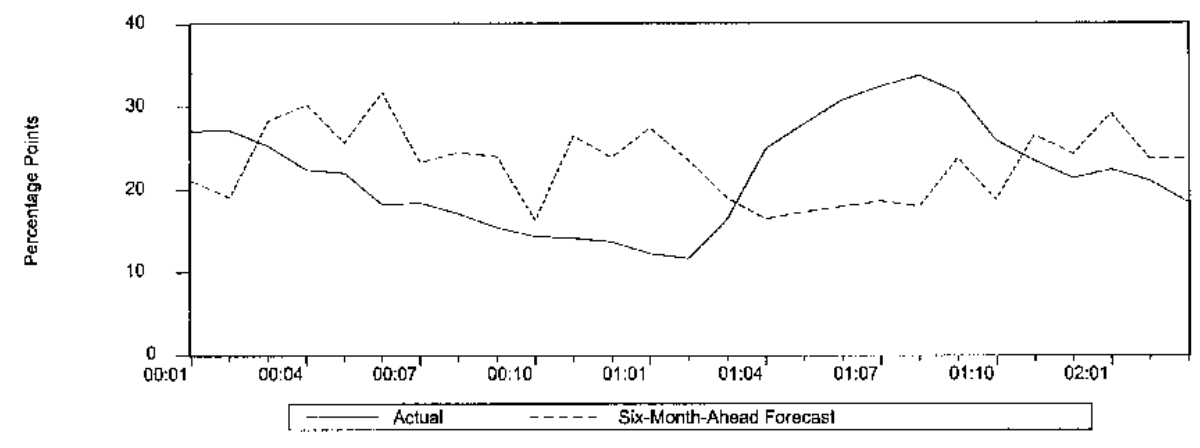

Figure 9. Cumulative Inflation Over Twelve Months (Seasonally Adjusted)

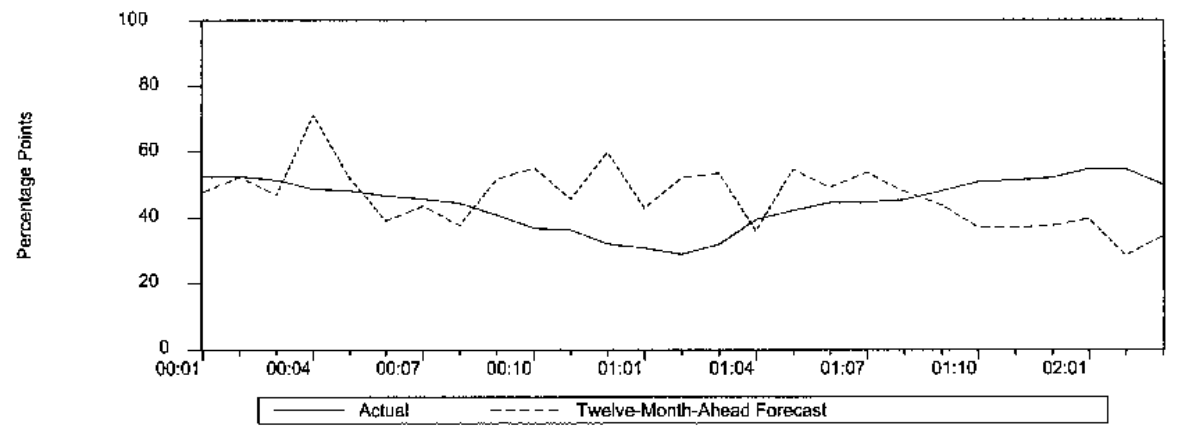




\section{REFERENCES}

Bai, J., 1997, "Estimating Multiple Breaks One at a Time," Econometric Theory, Vol. 13, pp. 315-52.

Bates, J. M. and Granger, C. W. J., 1969, "The Combination of Forecasts," Operations Research Quarterly, Vol. 20, pp. 319-25.

Chauvet, M., 2000, "Leading Indicators of Inflation for Brazil," Working Paper Series, No. 7, Banco Central do Brasil.

Diebold, F. X., and R. S. Mariano, 1994, "Comparing Predictive Accuracy," NBER Technical Working Paper 169, (Cambridge, Massachussetts: MIT Press).

Goodhart, C., and B. Hofmann, 1999, "Do Asset Prices Help to Predict Consumer Price Inflation," The Manchester School, Vol. 68, supplement.

Goodhart, C., and B. Hofmann, 2000, "Asset Prices and the Conduct of Monetary Policy," manuscript, London School of Economics.

Gordon, R. J., 1997, "The Time-Varying NAIRU and its Implications for Economic Policy," Journal of Economic Perspectives, Vol. 11, No. 1, pp. 11-32.

Gordon, R. J., 1998, "Foundations of the Goldilocks Economy: Supply Shocks and the TimeVarying NAIRU," Brookings Papers on Economic Activity.

Granger, C. W. J. and R. Ramanathan, 1984, "Improved Methods for Combining Forecasts," Journal of Forecasting, Vol. 3, pp. 197-204.

Grasmann, P., and F. Keerman, 2001, "An Indicator-Based Short-Term Forecast For Quarterly GDP in the Euro Area," European Commission Economic Paper, No. 154.

Kibritcioglu, A., 2001, "Causes of Inflation in Turkey: A Literature Survey with Special Reference to Theories of Inflation," Working Paper 01-0115, University of Illinois at Urbana-Champaign.

Lim, C. H., and L. Papi, 1997, "An Econometric Analysis of the Determinants of Inflation in Turkey," IMF Working Paper, No. 97/170, (Washington: International Monetary Fund).

Marcellino, M., J. H. Stock, and M. W. Watson, 2000, "Macroeconomic Forecasting in the Euro Area: Country Specific vs. Area-Wide Information," manuscript.

Okina, K., and S. Shiratsuka, 2001, "Asset Price Bubbles, Price Stability, and Monetary Policy: Japan's Experience," Bank of Japan Discussion Paper No. 2001-E-16, (Tokyo). 
Simone, A., 2001, "In Search of Coincident and Leading Indicators of Economic Activity in Argentina," IMF Working Paper, No. 01/30, (Washington: International Monetary Fund).

Staiger, D., J. H. Stock, and M. W. Watson, 1997, “The NAIRU, Unemployment and Monetary Policy," Journal of Economic Perspectives, Vol. 11, No. 1, pp. 33-49.

Stock, J. H., and M. W. Watson, 1999, "Business Cycle Fluctuations in U.S. Macroeconomic Time Series," Handbook of Macroeconomics, Vol. 1, ed. by J. B. Taylor and M. Woodford, pp. 3-64, (Amsterdam; New York: North Holland).

Stock, J. H., and M. W. Watson, 2001, "Forecasting Output and Inflation: The Role of Asset Prices," NBER Working Paper No. 8180, (Cambridge, Massachusetts: National Bureau of Economic Research).

West, K. D. (1996), "Asymptotic Inference about Predictive Ability," Econometrica, Vol. 64, 1067-1084. 